\title{
Characteristics of Runoff Variations and Attribution Analysis in the Poyang Lake Basin over the Past 55 Years
}

\author{
Ruonan Wang ${ }^{1,2}$, Wenqi Peng ${ }^{1}$, Xiaobo Liu ${ }^{1, *}$, Cuiling Jiang ${ }^{2, *}$, Wenqiang $\mathrm{Wu}^{1}$ and \\ Xuekai Chen ${ }^{1}$ \\ 1 State Key Laboratory of Simulation and Regulation of Water Cycle in River Basin, China Institute of Water \\ Resources and Hydropower Research, Beijing 100038, China; ruonanxin@163.com (P.W.); \\ pwq@iwhr.com (W.P.); wwqemail@126.com (W.W.); cxkkaixuan@163.com (X.C.) \\ 2 College of Hydrology and Water Resources, Hohai University, Nanjing 210098, China \\ * Correspondence: xbliu@iwhr.com (X.L.); jiangcuiling@hhu.edu.cn (C.J.)
}

Received: 27 December 2019; Accepted: 23 January 2020; Published: 28 January 2020

check for updates

\begin{abstract}
Spatial and temporal variations in hydrological series are affected by both climate change and human activities. A scientific understanding of the impacts of these two main factors on runoff will help to understand the response mechanism of the water cycle in a changing environment. This study focused on Poyang Lake Basin, which contains China's largest freshwater lake. Several approaches, including the Mann-Kendall trend test, cumulative anomaly method, Hurst exponent analysis, and slope change ratio of cumulative quantity (SCRCQ) method, were adopted to explore the characteristics of runoff variations and the respective impacts of climate change and human activities on runoff variations in the five subbasins. The results indicated that (1) from 1961 to 2015 , the runoff throughout the basin fluctuated, and it decreased significantly in the 2000s. (2) Different baseline periods and measurement periods were identified for each subbasin to analyse the spatial and temporal responses of runoff to climate change and human activities. (3) The runoff of each subbasin will exhibit anti-persistent features with different persistence times in the future. (4) Compared with those in the baseline period, in the first measurement period, precipitation was the main factor driving the runoff increase in the Ganjiang, Fuhe, Xinjiang and Raohe subbasins, with contribution rates of 50.91-63.47\%, and human activities played a supplementary role. However, in the second measurement period, as human activities intensified, they became the leading factor causing changes in runoff, with contribution rates between $59.57 \%$ and $92.49 \%$. Considering water shortages and the intensification of human activities, the impacts of human activities on runoff variations will require more attention in the future.
\end{abstract}

Keywords: runoff; climate change; human activities; quantitative estimation; SCRCQ; Poyang Lake Basin

\section{Introduction}

River runoff is a key part of the hydrological cycle in a basin, as runoff not only provides valuable water resources for human life and regional economic development but also is of crucial importance to the marine ecosystem due to its role in nutrient transport [1-3]. Many previous studies have shown that hydrological processes in a basin are directly or indirectly influenced by both climate change (e.g., changes in precipitation, temperature and evaporation) and human activities (e.g., agricultural irrigation, domestic and industrial water consumption, water and soil conservation, hydropower engineering and land use/land cover (LULC) changes) [4-7]. Due to climate change as well as large-scale utilization of water resources by human activities, river runoff is not consistent and 
undergoes significant changes [8-10]; as a result, approximately $31 \%$ of the 145 major rivers in the world have been shown to exhibit statistically significant increasing $(9 \%)$ or decreasing $(22 \%)$ trends in annual runoff in recent decades [11]. Changes in runoff could affect the rational allocation and utilization of water resources and even lead to some influence on the physical, chemical and biological processes of river ecosystems [12-15]. However, the characteristics of climate change and human activities vary from region to region, which may result in different influences on water resources [16]. Additionally, numerous studies have tried to investigate the influence of climate change and human activities on runoff variations using different methods that fall into three main groups [17-19] (Figure 1): (1) empirical statistical methods; (2) elasticity-based methods; (3) hydrological model methods.

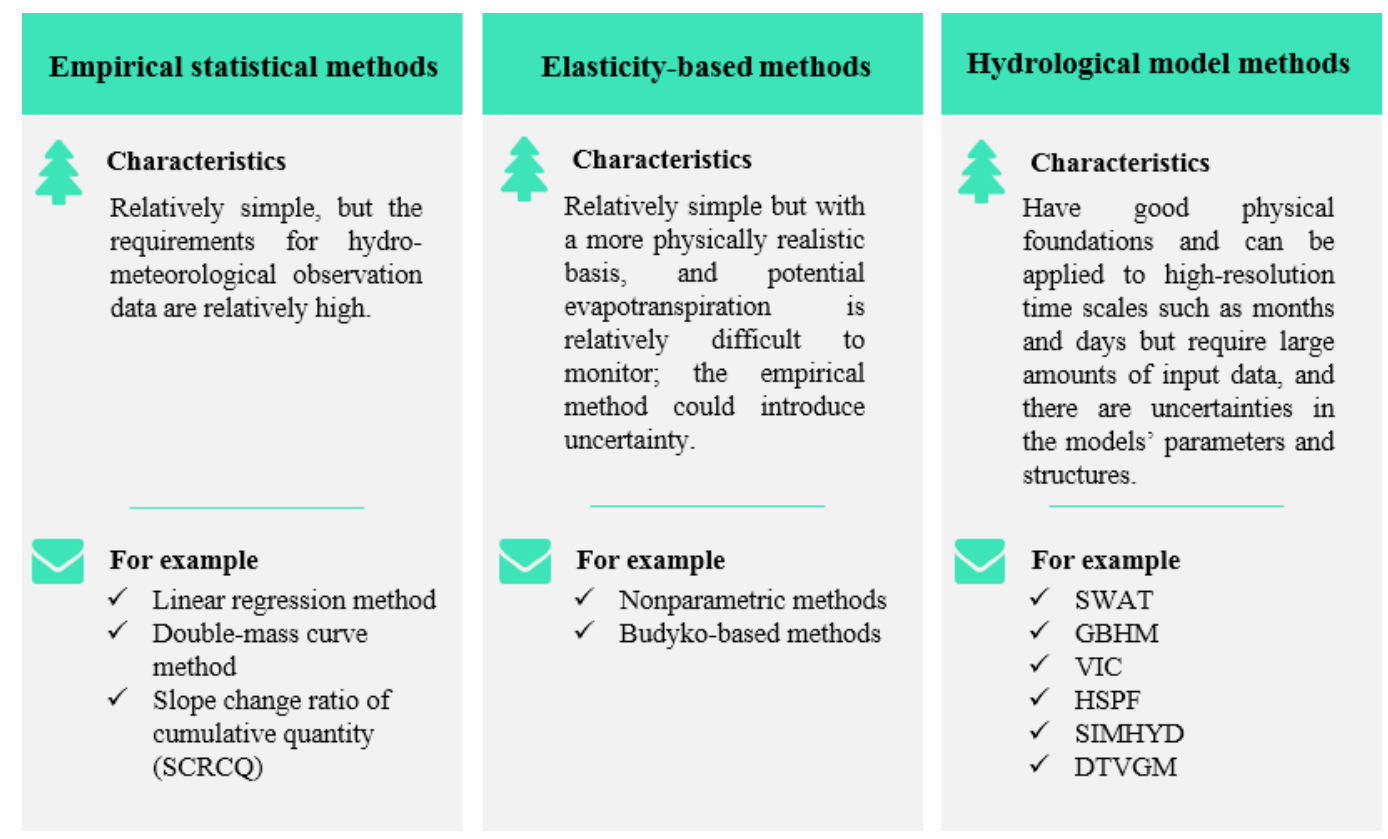

Figure 1. Characteristics of the three methods for detecting the quantitative impacts of climate changes and human activities on runoff changes.

Many researchers have conducted a wide range of studies on the attribution of runoff changes and quantitative analyses in the arid and semi-arid regions in northern China, such as the Yellow River Basin, Hei River Basin, and Wei River Basin. However, such studies are relatively rare in humid regions. In this study, we focus on the basin where China's largest freshwater lake is located-the Poyang Lake Basin (PYLB). Notably, according to statistics, in recent years, extreme hydrologic events such as floods, droughts, and abrupt drought-flood alternations have occurred frequently in the PYLB [20-22]. In the 1990s, the probability of occurrence of flood disasters in the PYLB was significantly higher than that in the 1950s, and three serious flood disasters occurred in 1995, 1996 and 1998 [23,24]. However, in the 2000s, drought disasters in the basin were frequent, such as those in 2003, 2006, 2007 and 2011 [25]. These frequent water resource problems seriously endanger people's lives and property in the PYLB, constrain the development of the local social economy, threaten the ecological health of the Poyang Lake region, and arouse great concern from all walks of life. Thus, analysing the patterns of runoff variations and their attributions are important for revealing the changes in water amounts and abrupt drought-flood alternations in the PYLB. Such study is also of great significance to the protection of the ecological environment of Poyang Lake.

Many efforts have been made in recent years to identify the impacts of climate change and human activities on runoff variations in the PYLB. Guo et al. used the Soil Water Assessment Tool (SWAT) model to examine the climate and land-use and land-cover effects on hydrology and streamflow in the Xinjiang River basin of Poyang Lake, but the contributions of these factors to variations in runoff 
were not considered, and the study area did not involve other subbasins [26]. Similar shortcomings also appeared in the studies by Hu et al. [27] and Liu et al. [28]. Moreover, Ye et al. used sensitivity analysis to quantify the impact of climate change and human activities on streamflow changes in the Gan, Xin and Fu Rivers [29]. However, a study by Wang noted that the sensitivity analysis technique could not exclude the impacts of human activities on streamflow changes during benchmark periods. Thus, the influences of human activities on streamflow changes as indicated by sensitivity analyses still involve human impacts during benchmark periods, which may produce misleading results [19]. Zhang et al. used three methods including Australia Water Balance Model, multivariate regression and sensitivity method to quantify the contributions of climate change and human activities on streamflow in the PYLB, and the fractional contributions were $73 \%$ and $27 \%$, respectively [30]. However, they ignored the fact that the impact of human activities had been strengthening. Zhao et al. used Pearson's test to address the regional cross-correlation between streamflow and climate variables. The results showed that streamflow in the Poyang Lake basin were more sensitive to changes in precipitation. However, contributions of climate variables to variations in streamflow and impact of human activities were not considered [31]. Therefore, the quantitative impacts of climate change and human activities on runoff variations in the PYLB need to be further studied. This study aims: (1) to explore variable trends and change points in runoff series in the PYLB from the perspective of space and time; (2) to identify the contribution rates of climate change and human activities that caused runoff alterations in different regions and periods by using the slope change ratio of cumulative quantity (SCRCQ) method; and (3) to discuss the impacts of climate and human activities on the runoff variations. The results of this study provide a new perspective for studying the long-term changes and impact factors of runoff in the PYLB, which will help enrich and improve the research content and methods for water resources in this area and provide a scientific basis for the rational development and efficient use of water resources and the protection of ecological safety in the basin.

\section{Study Area and Data}

\subsection{Study Area}

The PYLB is located on the south shore of the middle and lower reaches of the Yangtze River (Figure 2a) and has a drainage area of $16.22 \times 10^{4} \mathrm{~km}^{2}$. The basin is located in humid regions from $24^{\circ} 29^{\prime} \mathrm{N}-30^{\circ} 05^{\prime} \mathrm{N}$ latitude and $113^{\circ} 35^{\prime} \mathrm{E}-118^{\circ} 29^{\prime} \mathrm{E}$ longitude. The PYLB has some of the most obvious hydrological and climatic characteristics in the Yangtze River Basin, including the highest annual average precipitation, evaporation and runoff in the Yangtze River Basin [32]. The well-developed river system is mainly composed of five rivers (Ganjiang, Fuhe, Xinjiang, Raohe and Xiushui). Among them, Ganjiang is the largest river, running through the PYLB from south to north. The five rivers flow into Poyang Lake from the south, east and west and then discharge into the Yangtze River at Hukou to the north, forming a circular drainage system centred on Poyang Lake (Figure $2 b$ ). The runoff from the five rivers into the lake is an important indicator of the changes in the hydrological regime in Poyang Lake. The terrain in the basin is high in the south and low in the north and is surrounded by mountains on three sides to the south, east and west. Rolling hills are present in the central part, and plains are present in the north, namely, the Poyang Lake plain, which is one of the five plains in the Yangtze River Basin (Figure 2c). The topography of the basin is dominated by hills and mountainous regions, which account for approximately $78 \%$ of the total surface area (of which $36 \%$ are mountainous regions and $42 \%$ are hills), while $12.1 \%$ is plains area, and $9.9 \%$ is water [28]. The PYLB belongs to the subtropical humid monsoon climate zone, with a mild climate and abundant rainfall. The annual mean precipitation throughout the basin was $1641.40 \mathrm{~mm}$ from 1961-2015, but there was an asymmetric seasonal distribution of precipitation, with approximately $45 \%$ of the annual precipitation concentrated between April and June. The annual mean temperature is $17.97^{\circ} \mathrm{C}$, and the variation characteristics of inner-annual temperature show a single peak structure, reaching the hottest in July and the coldest in January, with the temperature difference between the two periods exceeding $20^{\circ} \mathrm{C}$. The annual mean 
potential evapotranspiration (PET) is $1092.18 \mathrm{~mm}$, and it exhibits inner-annual change characteristics similar to those of temperature (Figure 3). In this study, the total inflows into Poyang Lake include the sum of runoff at 7 hydrological stations, i.e., Waizhou (Ganjiang), Lijiadu (Fuhe), Meigang (Xinjiang), Hushan and Dufengkeng (Raohe), and Qiujin and Wanjiabu (Xiushui) (Figure 2b, Table 1). The total drainage area of these hydrological stations is $13.71 \times 10^{4} \mathrm{~km}^{2}$, accounting for $84.5 \%$ of the entire basin area, and the remaining $15.5 \%$ consists of the Poyang Lake intervening basin at $2.51 \times 10^{4} \mathrm{~km}^{2}$.

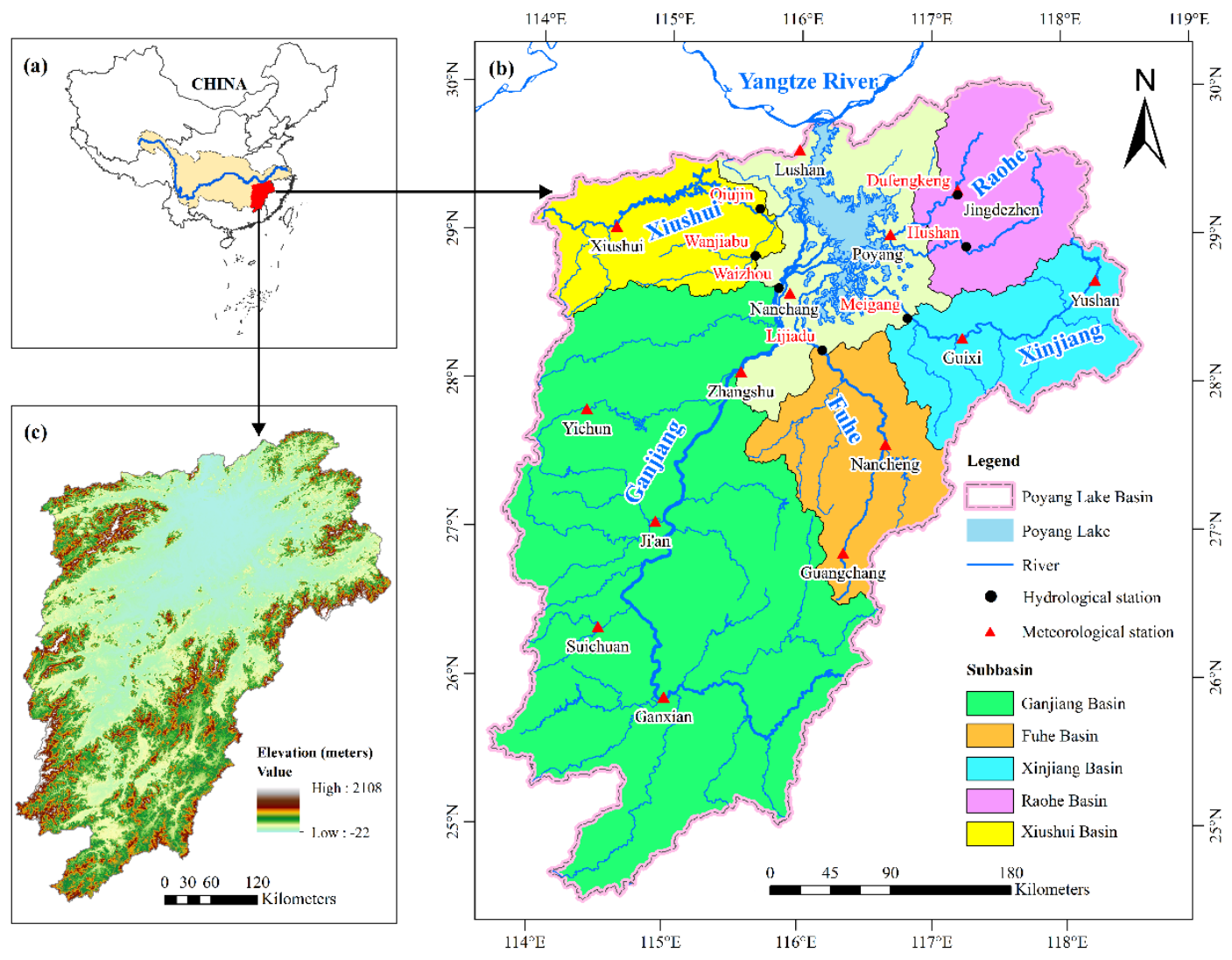

Figure 2. The study area: (a) location of the Poyang Lake Basin; (b) location of the five main subbasins, hydrological stations and meteorological stations; and (c) elevations in the Poyang Lake Basin.

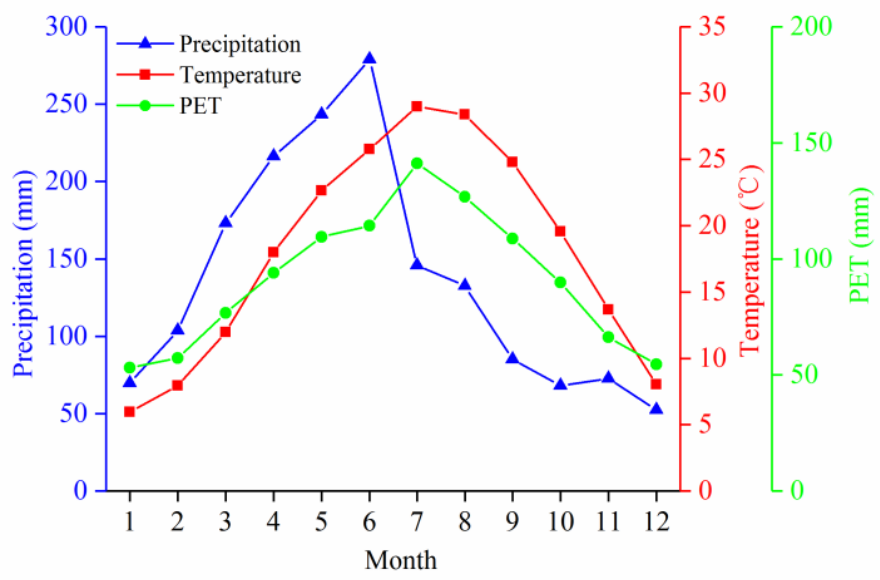

Figure 3. Inner-annual variations in the climatic factors in the Poyang Lake Basin (PYLB). 
Table 1. Information on the five subbasins investigated in this study.

\begin{tabular}{|c|c|c|c|c|c|c|c|c|c|}
\hline \multirow{2}{*}{ Subbasin } & \multirow{2}{*}{ River } & \multirow{2}{*}{$\begin{array}{c}\text { Drainage } \\
\text { Area }\left(\mathbf{k m}^{2}\right)\end{array}$} & \multirow{2}{*}{$\begin{array}{c}\text { Annual Mean } \\
\text { Runoff Depth }(\mathrm{mm})\end{array}$} & \multirow{2}{*}{$\begin{array}{c}\text { Annual Mean } \\
\text { Precipitation }(\mathrm{mm})\end{array}$} & \multicolumn{3}{|c|}{ Hydrological Station } & \multicolumn{2}{|c|}{ Meteorological Station } \\
\hline & & & & & Name & Latitude & Longitude & Name & Altitude (m) \\
\hline \multirow[t]{4}{*}{ Ganging } & \multirow[t]{4}{*}{ Ganjiang } & \multirow[t]{4}{*}{80948} & \multirow[t]{4}{*}{847} & \multirow[t]{4}{*}{1538.20} & \multirow[t]{4}{*}{ Waizhou } & \multirow[t]{4}{*}{$28.63^{\circ} \mathrm{N}$} & \multirow[t]{4}{*}{$115.83^{\circ} \mathrm{E}$} & Yichun & 131.3 \\
\hline & & & & & & & & Ji'an & 71.2 \\
\hline & & & & & & & & Suichuan & 126.1 \\
\hline & & & & & & & & Ganxian & 137.5 \\
\hline \multirow[t]{2}{*}{ Fuhe } & \multirow[t]{2}{*}{ Fuhe } & \multirow[t]{2}{*}{15811} & \multirow[t]{2}{*}{786} & \multirow[t]{2}{*}{1736.26} & \multirow[t]{2}{*}{ Lijiadu } & \multirow[t]{2}{*}{$28.22^{\circ} \mathrm{N}$} & \multirow[t]{2}{*}{$116.17^{\circ} \mathrm{E}$} & Nancheng & 80.8 \\
\hline & & & & & & & & Guangchang & 143.8 \\
\hline \multirow[t]{2}{*}{ Xinjiang } & \multirow[t]{2}{*}{ Xinjiang } & \multirow[t]{2}{*}{15535} & \multirow[t]{2}{*}{1174} & \multirow[t]{2}{*}{1859.91} & \multirow[t]{2}{*}{ Meigang } & \multirow[t]{2}{*}{$28.43^{\circ} \mathrm{N}$} & \multirow[t]{2}{*}{$116.82^{\circ} \mathrm{E}$} & Guixi & 60.8 \\
\hline & & & & & & & & Yushan & 116.3 \\
\hline \multirow{2}{*}{ Raohe } & Changjiang & 6374 & 1116 & \multirow[t]{2}{*}{1776.14} & Hushan & $28.92^{\circ} \mathrm{N}$ & $117.27^{\circ} \mathrm{E}$ & Jingdezhen & 61.5 \\
\hline & Le'anjiang & 5013 & 912 & & Dufengkeng & $29.16^{\circ} \mathrm{N}$ & $117.12^{\circ} \mathrm{E}$ & & \\
\hline \multirow[t]{3}{*}{ Xiushui } & Xiushui & 9914 & 854 & \multirow[t]{2}{*}{1577.36} & Qiujin & $29.10^{\circ} \mathrm{N}$ & $115.41^{\circ} \mathrm{E}$ & Xiushui & 146.8 \\
\hline & Liaohe & 3548 & 999 & & Wanjiabu & $28.85^{\circ} \mathrm{N}$ & $115.65^{\circ} \mathrm{E}$ & & \\
\hline & & & & & & & & Lushan & 1164.5 \\
\hline & & & & & & & & Poyang & 40.1 \\
\hline Region & & & & & & & & Nanchang & 46.9 \\
\hline & & & & & & & & Zhangshu & 30.4 \\
\hline
\end{tabular}




\subsection{Data}

Figure $2 \mathrm{~b}$ presents the locations of the seven hydrological stations and fourteen meteorological observation stations in the PYLB. The runoff observation data for the Ganjiang, Fuhe, Xinjiang, Raohe and Xiushui subbasins from 1961 to 2015 were obtained from the Jiangxi Hydrological Bureau, China. The meteorological data, including daily observations of precipitation, air temperature, sunshine hours, relative humidity and wind speed, during the period of 1961-2015 were provided by the China Meteorological Data Sharing Service System (http://data.cma.cn/). Based on the meteorological data, the PET at each meteorological station was then estimated following the Penman-Monteith method recommended by the Food and Agriculture Organization of the United Nations (FAO). Land use data for the years 1980, 1990, 1995, 2000, 2005, 2010 and 2015 were collected from the Resources and Environment Science Data Center at the Chinese Academy of Sciences (RESDC) (http://www.resdc.cn/).

\section{Methods}

\subsection{Mann-Kendall Trend Test}

The Mann-Kendall test is a rank-based non-parametric test recommended by the World Meteorological Organization (WMO) [33]. This method is very capable of testing linear or nonlinear trends and has been widely used to assess the significance of monotonic trends in meteorological and hydrological data time series. In this study, the method was applied to detect the variation trend in the runoff series.

In the Mann-Kendall test, if the $\mathrm{Z}$ value $>0$, the time series data have an increasing trend over time; if the contrary, the data have a decreasing trend. In this study, the significance level of the trend is set to 0.05 , which has a corresponding $Z$ value of 1.96 . Accordingly, a value of $|Z|>1.96$ indicates that the increasing or decreasing trend is statistically significant.

\subsection{Cumulative Anomaly}

The cumulative anomaly is commonly used to identify the tendency of the changes in meteorological and hydrological data, such as sequential precipitation, evaporation and runoff [34]. In this study, the cumulative anomaly method is used to identify inflection points by observing the changing tendency within runoff series in the PYLB.

\subsection{Hurst Exponent Analysis}

Hurst exponent (rescaled range (R/S)) analysis was pioneered by Harold Edwin Hurst in 1951 [35] and was improved by Mandelbrot and Wallis in 1969 [36]; this exponent can reveal trend components of a time series and show the intensity of the trend components. To date, Hurst exponent analysis has been used in many fields of study, including climatology, hydrology, geology and vegetation. If $H<0.5$, the time series is inconsistent, indicating that future trends will most likely be opposite of past trends. If $H>0.5$, the time series is consistent, indicating that the future trend will be consistent with the past trend. Finally, if $H=0.5$, the time series is random without sustainability. The grading table for the Hurst exponent is shown as follows (Table 2) [37]. To quantitatively describe the mean cycle of future changes in the time series, this study used the statistic value $V_{(\tau)}$, which has been introduced in detail in the literature [38], and the formula is:

$$
V_{(\tau)}=\left[\frac{R_{(\tau)}}{S_{(\tau)}}\right]_{\tau} / \sqrt{\tau}
$$

Here, the cycle length of the system $(T)$ is the corresponding time span $\tau$. This time span represents the length of persistent time in the future until the system completely loses its dependence on the initial condition. $\left.R_{(} \tau\right)$ and $\left.S_{(} \tau\right)$ are the extreme deviation sequence and the standard deviation sequence, respectively. 
Table 2. Grading table for the Hurst exponent.

\begin{tabular}{cccc}
\hline \multirow{2}{*}{ Grade } & \multicolumn{2}{c}{ Range of Hurst Exponent $(\boldsymbol{H})$} & \multirow{2}{*}{ Strength } \\
\cline { 2 - 3 } & Positive Correlation & Negative Correlation & \\
\hline I & $(0.50,0.55]$ & {$[0.45,0.50)$} & Weak \\
II & $(0.55,0.65]$ & {$[0.35,0.45)$} & Weaker \\
III & $(0.65,0.75]$ & {$[0.25,0.35)$} & Stronger \\
IV & $(0.75,0.85]$ & {$[0.15,0.25)$} & Strong \\
V & $(0.85,1.00]$ & {$[0.00,0.15)$} & Very strong \\
\hline
\end{tabular}

\subsection{SCRCQ Method}

The SCRCQ method was proposed by Wang et al. (2012) [39] and has been widely adopted in many studies [40-43].

Assume that the slopes of the linear relationships between the year and the cumulative runoff before and after a turning year are $S_{R b}$ and $S_{R a}\left(10^{8} \mathrm{~m}^{3} / \mathrm{a}\right)$, respectively, the slopes of the linear relationships between the year and the cumulative precipitation before and after a turning year are $S_{P b}$ and $S_{P a}(\mathrm{~mm} / \mathrm{a})$, respectively, and the slopes of the linear relationships between the year and the cumulative potential evaporation before and after a turning year are $S_{E b}$ and $S_{E a}(\mathrm{~mm} / \mathrm{a})$, respectively. The steps to calculate the contributions of climate change and human activities to runoff changes are defined as follows:

(1) Calculate the change ratios of runoff $\left(R_{S R}\right)$, precipitation $\left(R_{S P}\right)$ and potential evaporation $\left(R_{S E}\right)$ :

$$
\begin{aligned}
& R_{S R}=100 \times\left(S_{R a}-S_{R b}\right) / S_{R b}=100 \times\left(S_{R a} / S_{R b}-1\right) \\
& R_{S P}=100 \times\left(S_{P a}-S_{P b}\right) / S_{P b}=100 \times\left(S_{P a} / S_{P b}-1\right) \\
& R_{S E}=100 \times\left(S_{E a}-S_{E b}\right) / S_{E b}=100 \times\left(S_{E a} / S_{E b}-1\right)
\end{aligned}
$$

(2) Calculate the contributions of precipitation, evaporation and human activities on runoff changes, which are expressed as $C_{P}, C_{E}$ and $C_{H}$, respectively:

$$
\begin{gathered}
C_{P}=100 \times R_{S P} / R_{S R} \\
C_{P}=-100 \times R_{S E} / R_{S R} \\
C_{H}=100-C_{P}-C_{E}
\end{gathered}
$$

\section{Results}

\subsection{Changes in Precipitation and PET}

From 1961 to 2015, the annual mean precipitation in the PYLB was $1641.4 \mathrm{~mm}$, and the annual precipitation exhibited a non-significant increasing trend with a tendency coefficient of $25.37 \mathrm{~mm} / 10 \mathrm{a}$ and a $\mathrm{Z}$ value of 0.87 (Figure 4a). The inter-annual fluctuation range was relatively large, with a maximum of $2187.39 \mathrm{~mm}$ in 2012 and a minimum of $1103.50 \mathrm{~mm}$ in 1963, and the ratio between the two periods of 1.98. Additionally, the decadal changing trends in precipitation first increased and then decreased over the past five decades. Specifically, precipitation was lowest in the 1960s at $1538.80 \mathrm{~mm}$, and it increased to $1777.63 \mathrm{~mm}$ in the 1990s; then, it obviously decreased to $1638.25 \mathrm{~mm}$ during the 2000s. Contrary to precipitation, the annual PET throughout basin exhibited a notable downward trend and a $Z$ value of -7.07 , even passing the significance test at the $99 \%$ confidence level (Figure $4 \mathrm{~b}$ ). In addition, PET decreased at a rate of $49.71 \mathrm{~mm} / 10 \mathrm{a}$. The maximum annual PET occurred in 1964 at $1263.50 \mathrm{~mm}$, while the minimum occurred in 2001 at $909.32 \mathrm{~mm}$, and the ratio between them was 1.39. 


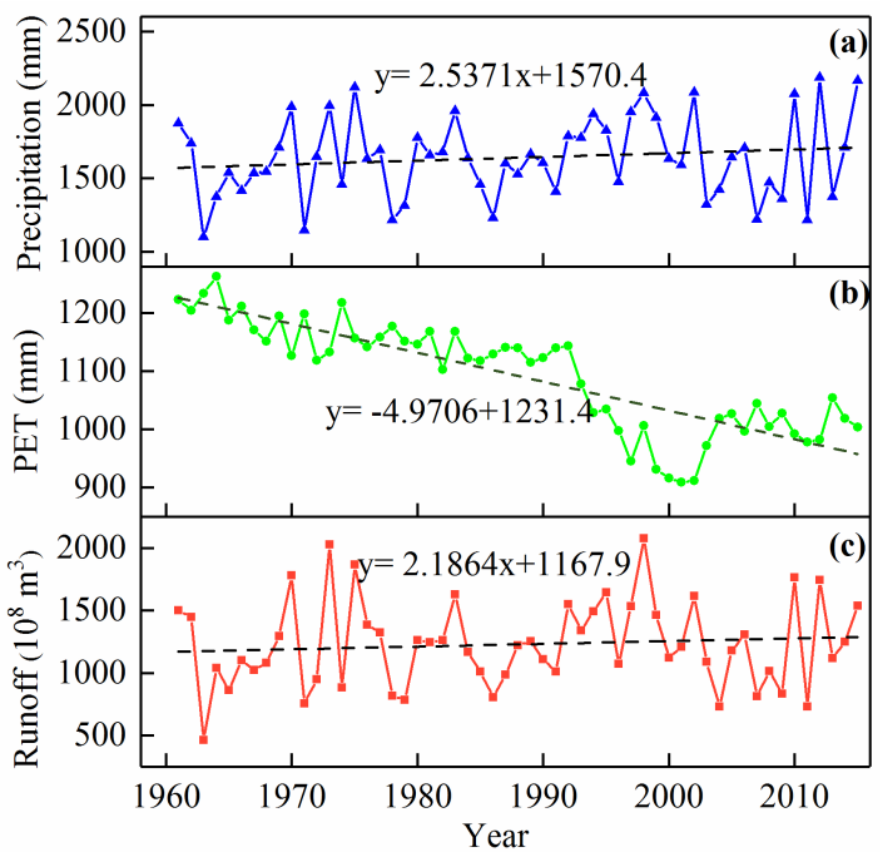

Figure 4. Temporal variations in (a) annual precipitation, (b) potential evapotranspiration (PET) and (c) runoff in the PYLB during 1961-2015.

The spatial distributions of annual mean precipitation and PET in the PYLB during 1961-2015 are illustrated in Figure 5. According to Figure 5a, precipitation in the PYLB spatially increases from south to north, with the maximum annual precipitation at the Lushan station in the north $(1996.25 \mathrm{~mm})$ and the minimum value at the Ganxian station in the south $(1426 \mathrm{~mm})$. Additionally, the figure shows obvious regional differences among the five subbasins; the maximum value of $1830.40 \mathrm{~mm}$ occurred in the Xinjiang subbasin, and the minimum of $1554.46 \mathrm{~mm}$ occurred in the Ganjiang subbasin. As shown in Figure 5b, the spatial distribution of the annual mean PET in the PYLB was different from that of precipitation. Precisely, the annual mean PET in the east of the basin was larger than that in the west. Among the 14 meteorological stations, the maximum of $1428.29 \mathrm{~mm}$ occurred at the Nancheng station in the east, and the minimum value of $721.90 \mathrm{~mm}$ occurred at the Xiushui station in the northwest. In addition, the comparison of each subbasin indicated that the maximum and minimum values occurred in the Xinjiang (1203.90 mm) and Xiushui (1019.50 mm) subbasins, respectively.
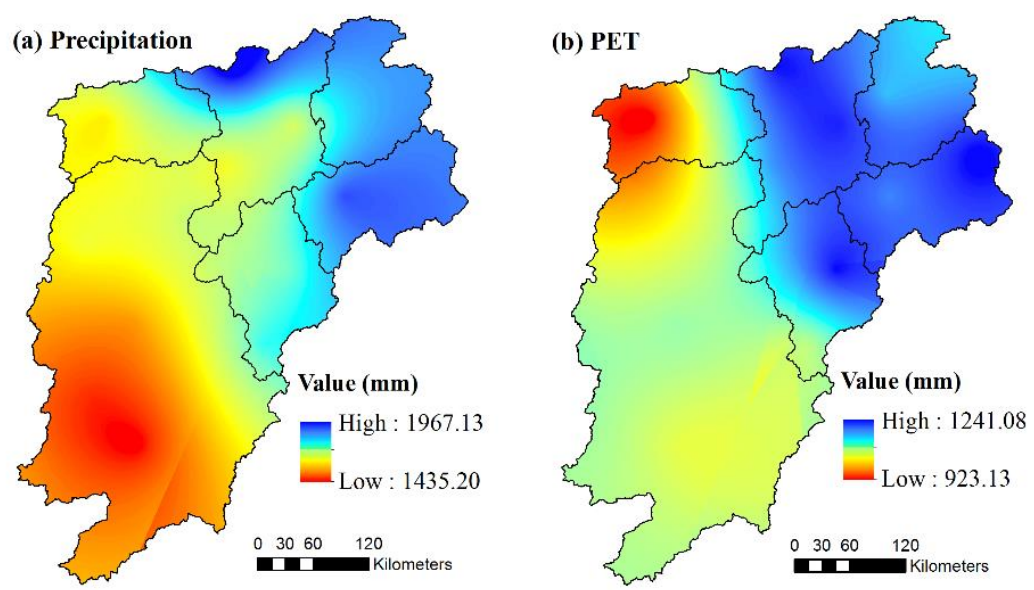

Figure 5. Spatial distributions of annual mean (a) precipitation and (b) PET in the PYLB during 1961-2015. 


\subsection{Changes in Runoff}

\subsubsection{Trend Change Characteristics}

The annual mean runoff was $1229.16 \times 10^{8} \mathrm{~m}^{3}$ for the entire basin for the period from 1961-2015, and the runoff exhibited fluctuating inter-annual variations (Figure 4c), indicating that it varied greatly from year to year. The annual maximum runoff was $2076.11 \times 10^{8} \mathrm{~m}^{3}$ and occurred in 1998 , while the minimum was $463.39 \times 10^{8} \mathrm{~m}^{3}$ and occurred in 1963 . The temporal variation trends in runoff for the PYLB from 1961-2015 were analysed in this study based on linear regression analysis, which showed an increasing trend with a slope of $21.86 \times 10^{8} \mathrm{~m}^{3} / 10 \mathrm{a}$. The Mann-Kendall statistic of 0.67 indicated that this change trend was not significant. The decadal analysis results indicated that runoff increased first and then decreased over the past 55 years, which is broadly consistent with the results of Luo et al. [44]; namely, the runoff peaked in the 1990s at $1430.15 \times 10^{8} \mathrm{~m}^{3}$ and then decreased to $1191.35 \times 10^{8} \mathrm{~m}^{3}$ in the 2000s.

Figure 6 shows how the runoff changed in each subbasin, which can be summarized as follows: there were some similarities but also differences between the subbasins. Runoff in the Ganjiang, Xinjiang, Raohe, and Xiushui subbasins showed increasing trends, among which the runoff in the Ganjiang subbasin increased the most obviously with a tendency coefficient of $7.24 \times 10^{8} \mathrm{~m}^{3} / 10 \mathrm{a}$ from 1961-2015. In contrast, the runoff in the Fuhe Basin showed a decreasing trend at $-0.16 \times 10^{8} \mathrm{~m}^{3} / 10 \mathrm{a}$. The abovementioned temporal change characteristics were also validated by the Mann-Kendall trend test, and the $Z$ values were 0.58 (Ganjiang), -0.09 (Fuhe), 1.19 (Xinjiang), 1.03 (Raohe) and 1.42 (Xiushui). In addition, Mann-Kendall test results indicated that the runoff series of the five subbasins did not reach the confidence level of $95 \%$, which means that the change trends were not significant.

From a decadal point of view, the runoff in each subbasin over the past 55 years experienced a repeated "increasing-decreasing" process (Figure 6). According to the statistical results, the runoff in each subbasin increased most dramatically in the 1990s, especially in the Raohe and Xiushui subbasins, which increased by $34.19 \%$ and $34 \%$, respectively, from the values in the 1980s. Meanwhile, the smallest increase occurred in the Fuhe subbasin at $7.07 \%$. The runoff series in the five subbasins have decreased significantly since 2000, among which the runoff in the Fuhe subbasin was even less than that during the 1960s.

In terms of the inter-annual fluctuations in the runoff in the five subbasins, the coefficients of variation (Cv) from 1961 to 2015 were 0.37 (Fuhe) $>0.35$ (Raohe) $>0.34$ (Xiushui) $>0.33$ (Xinjiang) $>0.28$ (Ganjiang), indicating that the inter-annual variations in runoff in the Fuhe subbasin was the most obvious with the highest volatility, while the annual runoff in the Ganjiang subbasin was relatively stable.
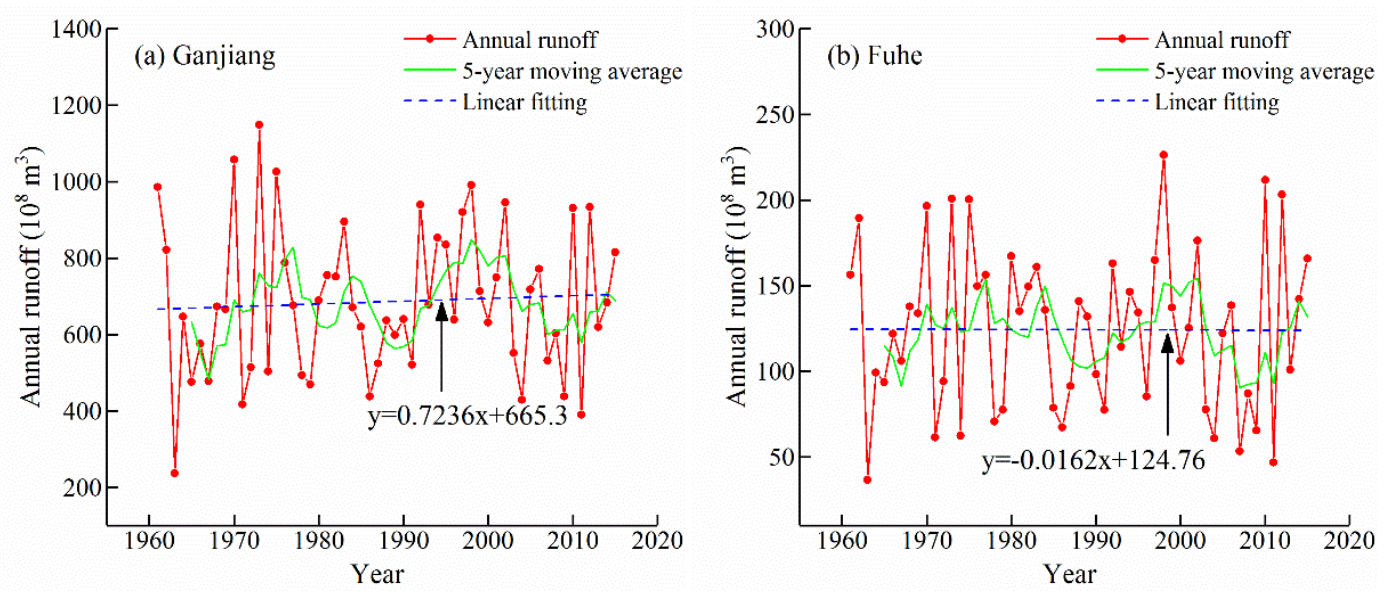

Figure 6. Cont. 

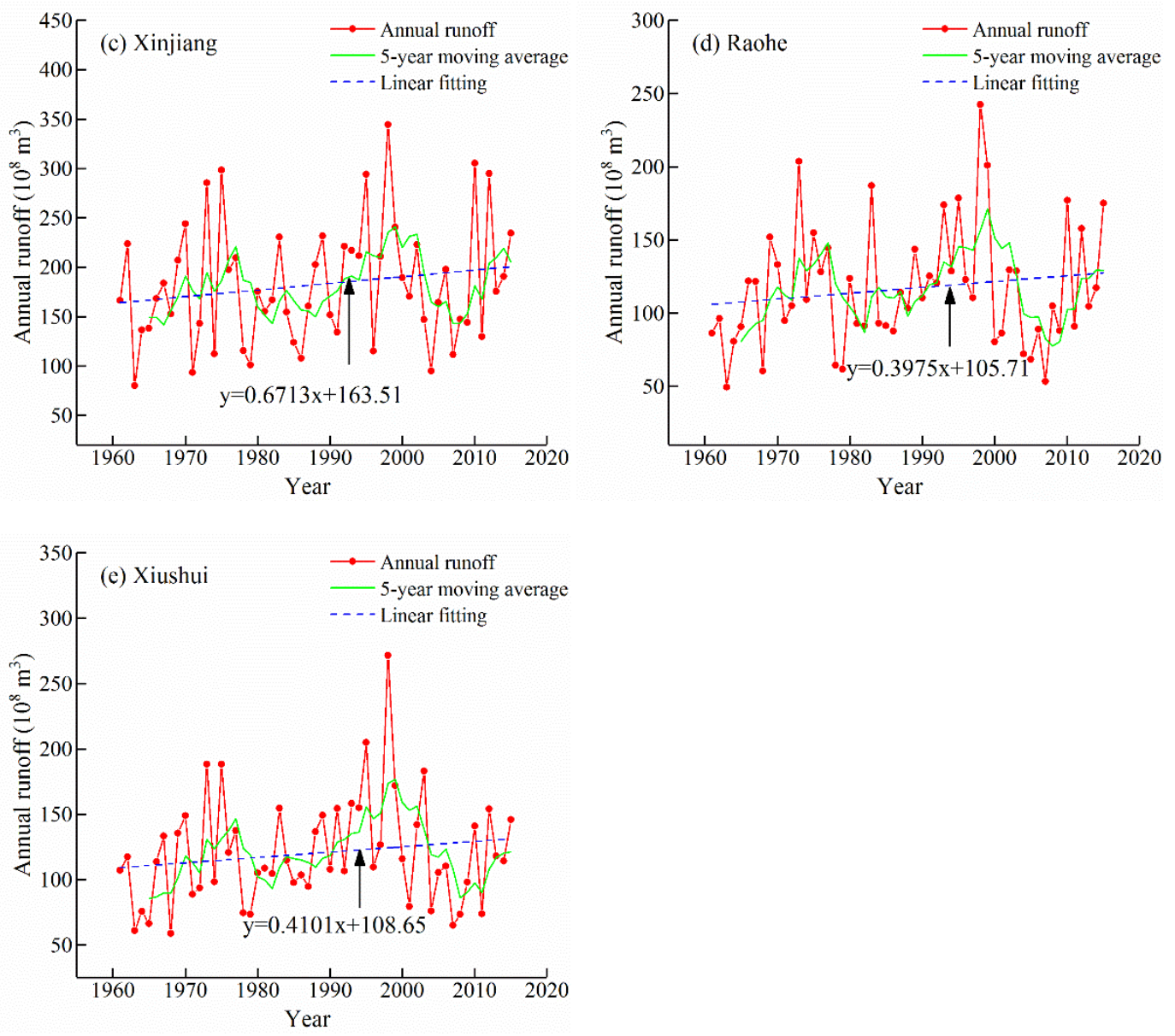

Figure 6. Temporal variations in annual runoff for the five subbasins: (a) Ganjiang; (b) Fuhe; (c) Xinjiang; (d) Raohe; and (e) Xiushui.

\subsubsection{Abrupt Change Characteristics}

To analyse the inflection point of the runoff in each subbasin from 1961-2015, the cumulative anomaly method was used in this study, and the results are shown in Figure 7. As shown by the cumulative anomaly curves, the runoff curves for the Ganjiang, Fuhe and Xinjiang subbasins all had two significant inflection points in 1991 and 2002. That is, runoff showed a decreasing trend from 1961 to 1991, an increasing trend from 1992 to 2002, and a decreasing trend after 2002. For the Raohe and Xiushui subbasins, the cumulative anomaly curves of runoff reached their lowest values in 1988 and their highest values in 1999 and 2002, respectively. Therefore, the significant inflection points of runoff occurred in 1988 and 1999 for Raohe and 1988 and 2002 for Xiushui. As such, the entire study period of 1961-2015 could be divided based on these inflection points (Table 3). The periods from 1961-1991 and 1961-1988 were designated as the reference baseline periods for the runoff changes in the corresponding subbasin. Other periods (i.e., 1992-2002 and 2003-2015 for the Ganjiang, Fuhe and Xinjiang subbasins, 1989-1999 and 2000-2015 for the Raohe subbasin, and 1989-2002 and 2002-2015 for the Xiushui subbasin) were regarded as the measurement periods.

Compared with the values obtained during the baseline period (Ta), the annual mean runoff during the first measurement period $(\mathrm{Tb})$ increased for all subbasins but with different magnitudes. In addition, the annual mean runoff during the second measurement period (Tc) continued to increase for the Xinjiang and Xiushui subbasins, although the increase ranges were smaller than those in the period $\mathrm{Tb}$. However, runoff decreased slightly for the Ganjiang, Fuhe and Raohe subbasins (Table 3). 

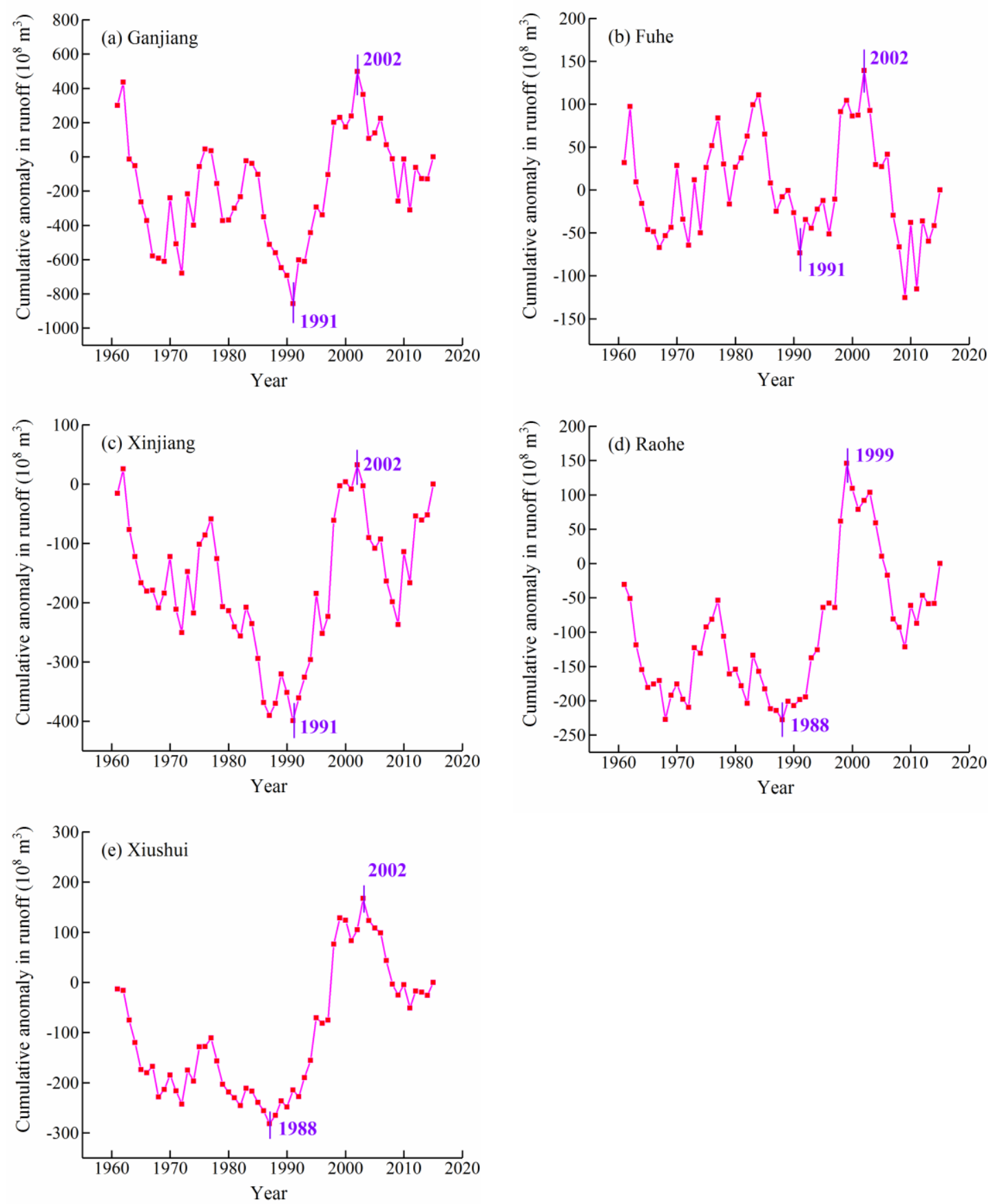

Figure 7. Cumulative anomalies in annual runoff and the turning years in each subbasin: (a) Ganjiang; (b) Fuhe; (c) Xinjiang; (d) Raohe; and (e) Xiushui.

Table 3. Period divisions for the five subbasins and annual mean runoff during different periods.

\begin{tabular}{|c|c|c|c|c|c|c|}
\hline \multirow{2}{*}{ Subbasin } & \multicolumn{2}{|c|}{ Baseline Period } & \multicolumn{4}{|c|}{ Measurement Periods } \\
\hline & $\mathbf{T}_{\mathbf{a}}$ & $\begin{array}{c}R_{a} \\
\left(10^{8} \mathrm{~m}^{3} / \mathrm{a}\right)\end{array}$ & $\mathbf{T}_{\mathbf{b}}$ & $\begin{array}{c}R_{b} \\
\left(10^{8} \mathrm{~m}^{3} / \mathrm{a}\right)\end{array}$ & $\mathbf{T}_{\mathrm{c}}$ & $\begin{array}{c}R_{c} \\
\left(10^{8} \mathrm{~m}^{3} / \mathrm{a}\right)\end{array}$ \\
\hline Ganjiang & 1961-1991 & 657.93 & 1992-2002 & 808.73 & 2003-2015 & 647.24 \\
\hline Fuhe & 1961-1991 & 121.95 & 1992-2002 & 143.63 & 2003-2015 & 113.60 \\
\hline Xinjiang & 1961-1991 & 169.43 & $1992-2002$ & 221.55 & $2003-2015$ & 179.82 \\
\hline Raohe & 1961-1988 & 108.72 & 1989-1999 & 150.79 & 2000-2015 & 107.73 \\
\hline Xiushui & 1961-1988 & 110.66 & 1989-2002 & 146.56 & 2003-2015 & 112.07 \\
\hline
\end{tabular}




\subsubsection{Long-Term Memory Characteristics}

The Hurst exponent $(\mathrm{H})$ was used to analyse the persistence of runoff, and the fitting curves of $R / S-\tau / 2$ and $V(\tau)-\lg \tau$ were generated and are plotted in Figure 8. As shown in Table 4, the $H$ values for runoff in the Ganjiang, Fuhe, Xinjiang, Raohe and Xiushui subbasins were 0.39, 0.36, 0.26, 0.30 and 0.35 , respectively. These results indicated that the future trends in runoff in the five subbasins would be the opposite of the past trends. That is, in the future, there will be decreasing trends in runoff in the Ganjiang, Xinjiang, Raohe and Xiushui subbasins and an increasing trend in runoff in the Fuhe subbasin.

According to the grading table of the Hurst exponents (Table 2), the continuous intensities of runoff in the Ganjiang, Fuhe and Xiushui subbasins were weak with persistence strengths of Grade II, and the intensities were strong for the Xinjiang and Raohe subbasins with persistence strengths of Grade III. The runoff persistence times (T) were 9 years (Ganjiang, Fuhe and Xinjiang subbasins) and 6 years (Raohe and Xiushui subbasins). This finding indicates that within their persistence times, runoff in the Ganjiang, Xinjiang, Raohe and Xiushui subbasins will continuously decrease, whereas runoff in the Fuhe subbasin will continuously increase.
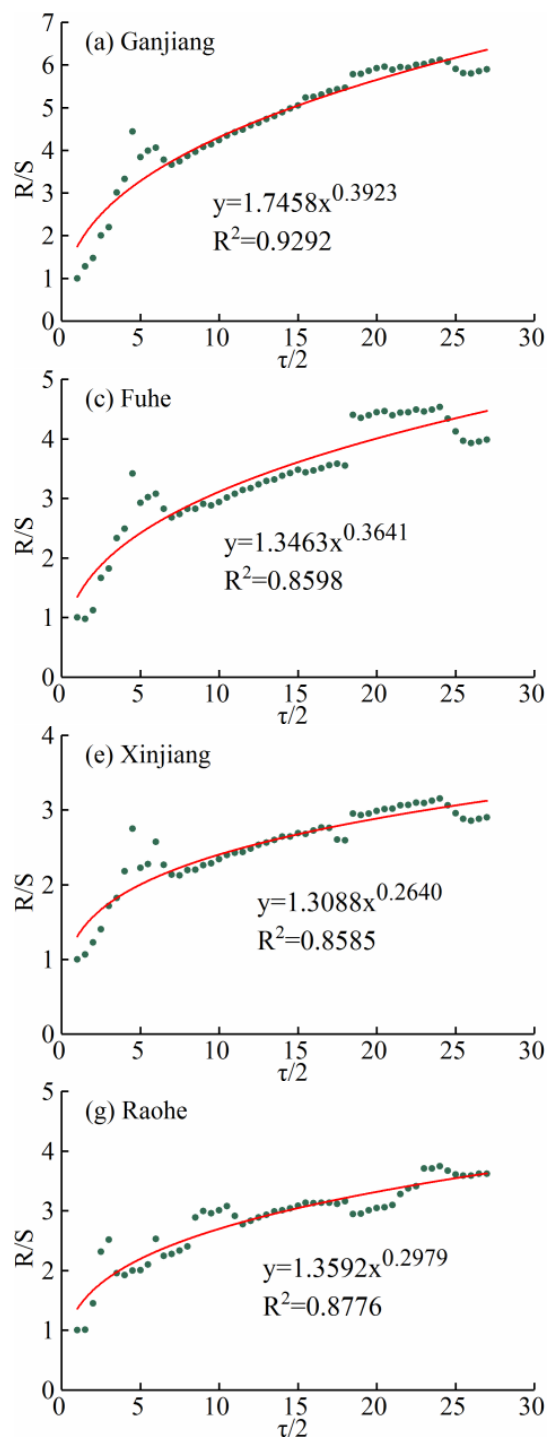
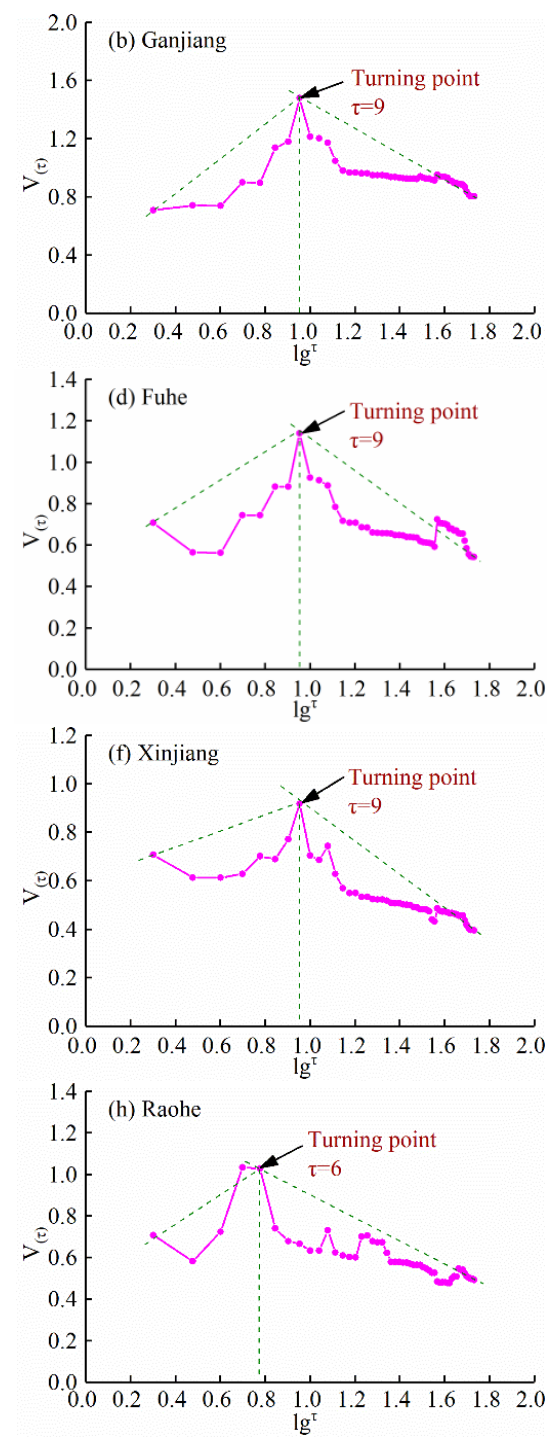

Figure 8. Cont. 

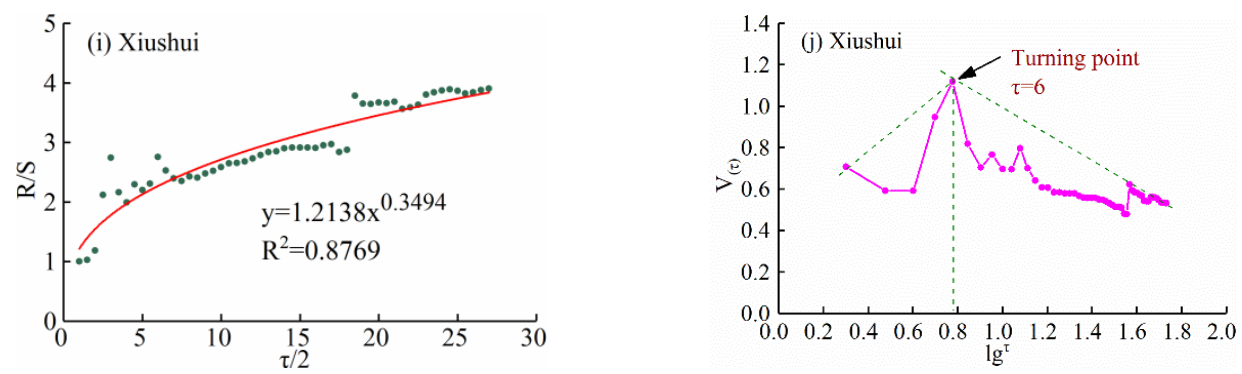

Figure 8. Fitting curves for the results of Hurst exponent analysis and the persistent times of runoff in the five subbasins.

Table 4. Results of Hurst exponent analysis and the future sustainability features of runoff in the five subbasins.

\begin{tabular}{ccccccc}
\hline Subbasin & H & Correlation & Strength & T (a) & Change Trend \\
& & & & Historical & Future \\
\hline Ganjiang & 0.39 & Negative & Weaker & 9 & $\uparrow$ & $\downarrow$ \\
Fuhe & 0.36 & Negative & Weaker & 9 & $\downarrow$ & $\uparrow$ \\
Xinjiang & 0.26 & Negative & Stronger & 9 & $\uparrow$ & $\downarrow$ \\
Raohe & 0.30 & Negative & Stronger & 6 & $\uparrow$ & $\downarrow$ \\
Xiushui & 0.35 & Negative & Weaker & 6 & $\uparrow$ & $\downarrow$ \\
\hline
\end{tabular}

\subsubsection{Quantification of the Influences of Climatic and Human Activities}

The relationships between runoff and climatic factors in the PYLB were explored in this study using the correlation analysis method. The analysis results indicated that runoff in the PYLB was closely correlated with precipitation, with a correlation coefficient of 0.92 that passed the significance level of 0.01. However, the correlational relationships between runoff and both temperature and PET were not significant $(-0.06$ and -0.23 , respectively). The results suggested that temperature and PET in the PYLB had limited influence on Poyang Lake inflow, whereas precipitation was the main climatic factor. Thus, in this study, only precipitation was considered in the quantitative assessment of the impacts of climate change on runoff changes.

Figures 9 and 10 illustrate the scatter distributions, fitted lines and fitted best linear relationships between the year and cumulative data (runoff and precipitation) before and after the turning years for the five subbasins. The coefficients of determination $\left(R^{2}\right)$ between year and each factor were high and exceeded 0.98. Meanwhile, the confidence levels of the $p$ values were $<0.0001$. Thus, the correlation between each factor and year was high. The slope $\left(S_{R}\right.$ and $\left.S_{P}\right)$ of each fitted line was extracted from the equations shown in Figures 9 and 10, and the values are listed in Table 5.

The quantitative impacts of precipitation on runoff changes were calculated using Equation (5). As shown in Table 5, compared with the baseline period (Ta), the main factor resulting in runoff changes in the Ganjiang, Fuhe, Xinjiang, and Raohe subbasins was precipitation in the Tb period, while precipitation was not the main factor in the Xiushui subbasin. However, the impact of human activities on runoff changes in the five subbasins occupied the dominant position in the most recent decade (Tc). 

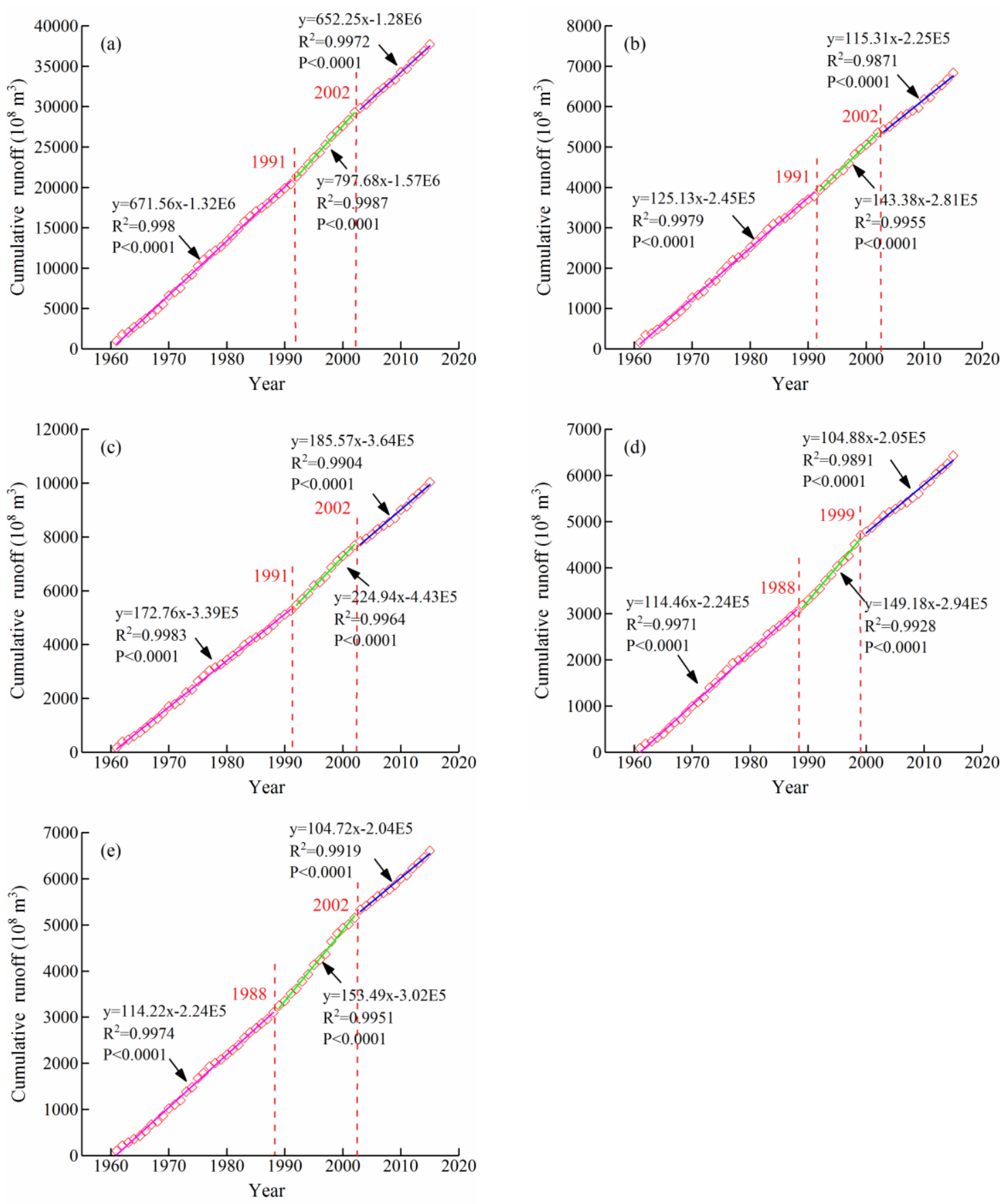

Figure 9. Relationships between year and cumulative runoff for the five subbasins: (a) Ganjiang; (b) Fuhe; (c) Xinjiang; (d) Raohe; and (e) Xiushui. 

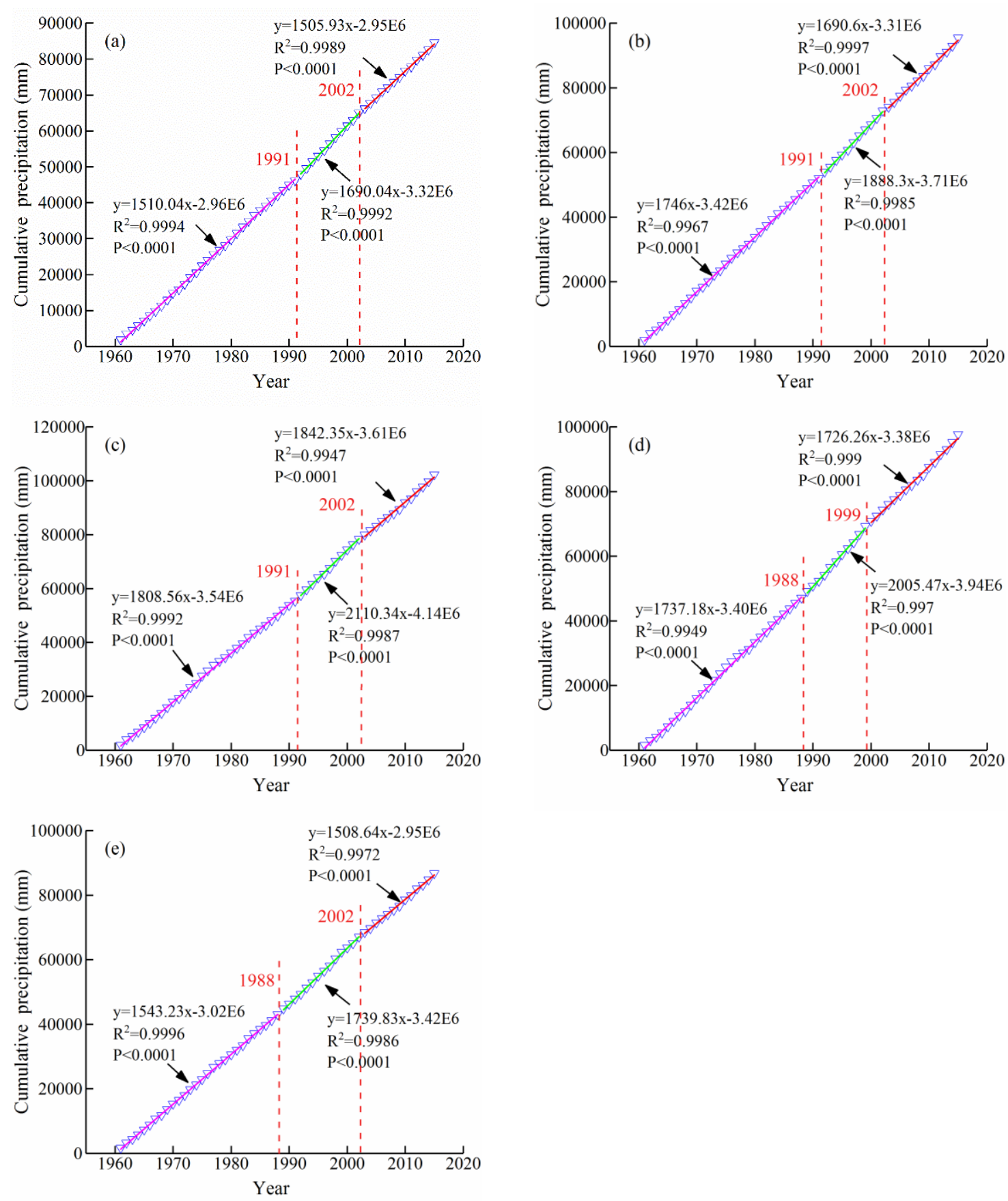

Figure 10. Relationships between year and cumulative precipitation for the five subbasins: (a) Ganjiang; (b) Fuhe; (c) Xinjiang; (d) Raohe; and (e) Xiushui. 
Table 5. Contributions of precipitation and human activities to runoff changes in the five subbasins.

\begin{tabular}{|c|c|c|c|c|c|c|c|c|}
\hline \multirow[t]{2}{*}{ Subbasins } & \multicolumn{2}{|c|}{ Periods } & \multirow[t]{2}{*}{$S_{R}\left(10^{8} \mathrm{~m}^{3} / \mathrm{a}\right)$} & \multirow[t]{2}{*}{$S_{P}(\mathrm{~mm} / \mathrm{a})$} & \multirow[t]{2}{*}{$\Delta S_{R}(\%)$} & \multirow[t]{2}{*}{$\Delta S_{P}(\%)$} & \multicolumn{2}{|c|}{$\begin{array}{c}\text { Contribution to the Runoff } \\
\text { Changes }\end{array}$} \\
\hline & & & & & & & $C_{P}(\%)$ & $C_{H}(\%)$ \\
\hline \multirow[t]{3}{*}{ Ganjiang } & $\mathrm{T}_{\mathrm{a}}$ & 1961-1991 & 671.56 & 1510.04 & & & & \\
\hline & $\mathrm{T}_{\mathrm{b}}$ & 1992-2002 & 797.68 & 1690.04 & 18.78 & 11.92 & 63.47 & 36.53 \\
\hline & $\mathrm{T}_{\mathrm{c}}$ & 2003-2015 & 652.25 & 1505.93 & -2.88 & -0.27 & 9.47 & 90.53 \\
\hline \multirow[t]{3}{*}{ Fuhe } & $\mathrm{T}_{\mathrm{a}}$ & 1961-1991 & 125.13 & 1746 & & & & \\
\hline & $\mathrm{T}_{\mathrm{b}}$ & 1992-2002 & 143.38 & 1888.3 & 14.58 & 8.15 & 55.88 & 44.12 \\
\hline & $\mathrm{T}_{\mathrm{c}}$ & 2003-2015 & 115.31 & 1690.6 & -7.85 & -3.17 & 40.43 & 59.57 \\
\hline \multirow[t]{3}{*}{ Xinjiang } & $\mathrm{T}_{\mathrm{a}}$ & 1961-1991 & 172.76 & 1808.56 & & & & \\
\hline & $\mathrm{T}_{\mathrm{b}}$ & 1992-2002 & 224.94 & 2110.34 & 30.20 & 16.69 & 55.25 & 44.75 \\
\hline & $\mathrm{T}_{\mathrm{c}}$ & 2003-2015 & 185.57 & 1842.35 & 7.41 & 1.87 & 25.20 & 74.80 \\
\hline \multirow[t]{3}{*}{ Raohe } & $\mathrm{T}_{\mathrm{a}}$ & 1961-1988 & 114.46 & 1737.18 & & & & \\
\hline & $\mathrm{T}_{\mathrm{b}}$ & 1989-1999 & 149.18 & 2005.47 & 30.33 & 15.44 & 50.91 & 49.09 \\
\hline & $\mathrm{T}_{\mathrm{c}}$ & 2000-2015 & 104.88 & 1726.26 & -8.37 & -0.63 & 7.51 & 92.49 \\
\hline \multirow[t]{3}{*}{ Xiushui } & $\mathrm{T}_{\mathrm{a}}$ & 1961-1988 & 114.22 & 1543.23 & & & & \\
\hline & $\mathrm{T}_{\mathrm{b}}$ & 1989-2002 & 153.49 & 1739.83 & 34.38 & 12.74 & 37.05 & 62.95 \\
\hline & $\mathrm{T}_{\mathrm{c}}$ & 2003-2015 & 104.72 & 1508.64 & -8.32 & -2.24 & 26.95 & 73.05 \\
\hline
\end{tabular}




\section{Discussion}

\subsection{Different Inflection Points in the Runoff Changes}

In a previous study on runoff in the PYLB, Ye et al. subjectively used only 1960-1969 as the reference baseline period [29]. However, Liu et al. [45] and Xiao et al. [46] noted that the inflection points of the runoff series were different in the five rivers in the PYLB, and they believed that the runoff series of each river had only one inflection point. Considering the regional spatial and temporal differences, the above studies are not sufficient to fully understand the characteristics of runoff variations in the PYLB.

The results of this research indicated that the runoff series of all five subbasins had two inflection points, but they were not the same; namely, inflection points appeared in 1991 and 2002 for the Ganjiang, Fuhe and Xinjiang subbasins, 1988 and 1999 for the Raohe subbasin, and 1988 and 2002 for the Xiushui subbasin. According to the above analysis, the correlation between runoff and precipitation in the PYLB was strong and not sensitive to other climatic factors; we believe that the abrupt characteristics of the runoff series in different regions were mainly caused by the uneven spatial and temporal distributions of precipitation. By further analysing the abrupt characteristics of the precipitation series, the inflection points of precipitation in each subbasin were clearly consistent with the runoff (Figure 11). Therefore, the rationality of the above conjecture is further proven.
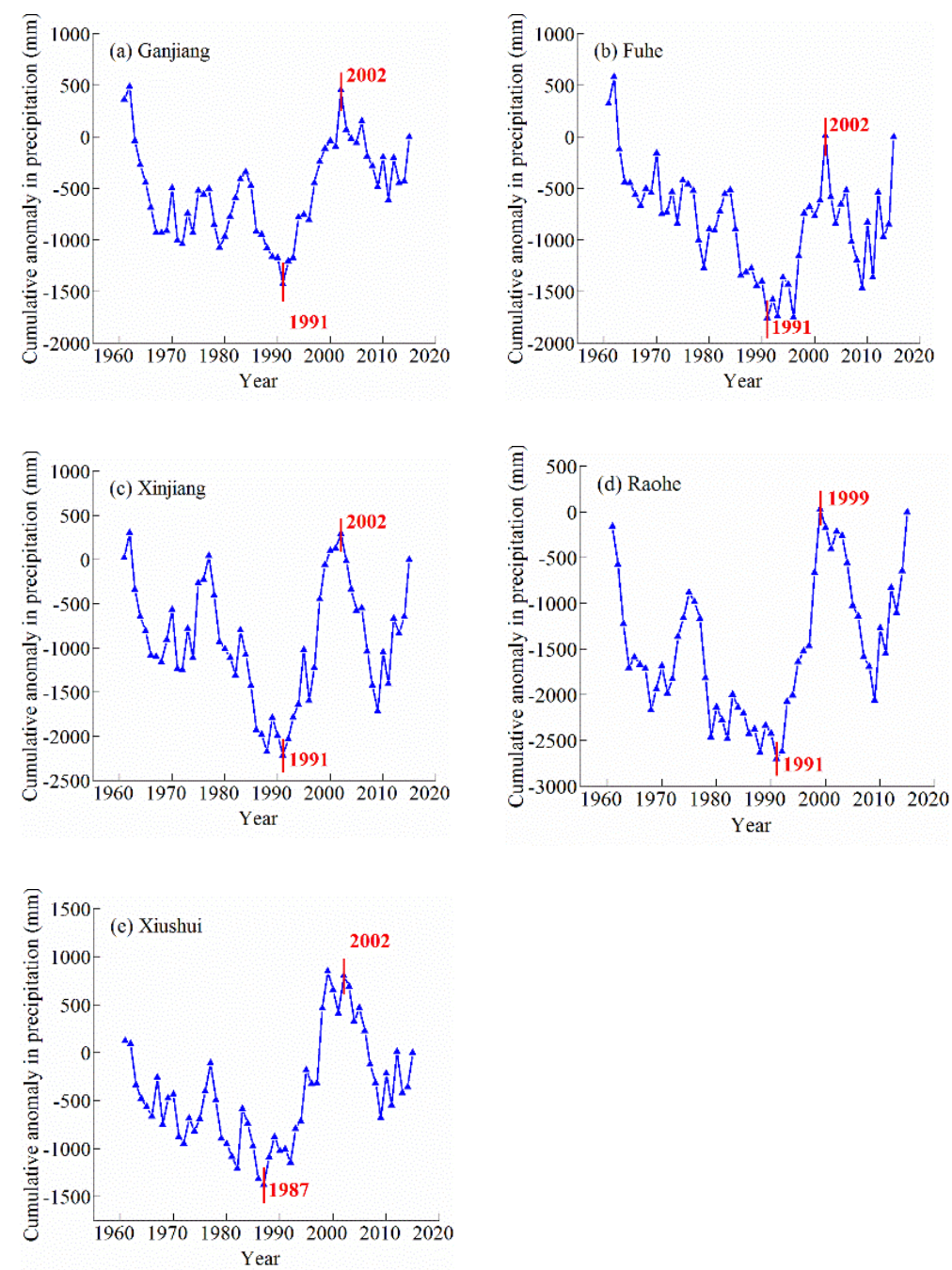

Figure 11. Cumulative anomalies in annual precipitation and the inflection points in each subbasin: (a) Ganjiang; (b) Fuhe; (c) Xinjiang; (d) Raohe; and (e) Xiushui. 


\subsection{Impacts of Precipitation on the Runoff Changes}

The much stronger correlation between runoff and precipitation than between runoff and other climatic factors in the PYLB was proven in this research, which is consistent with the research findings of Zhao et al. [31]. Additionally, Zhang et al. noted that the upward trend in runoff series may be related to the simultaneous increases in the runoff coefficient and precipitation of each tributary in the PYLB [47]. Moreover, the research by Guo et al. also showed that the impact of climate change on the runoff coefficient of the PYLB has remained very significant for the last half-century [48].

\subsection{Impacts of Human Activities on Runoff Changes}

According to the results of this research, we know that during the 2000s, the contribution rate of precipitation to runoff changes in each subbasin gradually decreased, while the impact of human activities gradually increased, and the contribution rates of human activities in each subbasin were between $59.57 \%$ and $92.49 \%$. That is, as human activities have intensified, they have played a leading and positive role in the factors impacting runoff changes in the most recent decade in the PYLB. In addition, this phenomenon is increasingly common in various regions of China, such as Dongting Lake (58.89-78.33\%) and the Hanjiang River Basin (56.5-57.2\%) of the Yangtze River Basin, the Yellow River Basin (91.7\%) and the Liao River Basin (80\%) [49-52].

In general, the impacts of human activities on hydrological processes are mainly reflected in two aspects [17,53-55]: (1) direct impacts: for example, the construction and operation of large reservoirs and dams can change the natural characteristics of runoff and redistribute runoff in time and space, and water withdrawal by agriculture, industry and life is another direct factor affecting runoff; and (2) indirect impacts: for example, soil and water conservation practices or urbanization can change the LULC (Land Use and Land Cover) by changing the characteristics of the underlying surface of the basin, thus affecting the generation and collection of runoff.

To date, $24.2 \times 10^{4}$ water storage projects have been built in the PYLB with a total capacity of $317.7 \times 10^{8} \mathrm{~m}^{3}$; most of these projects are ponds and small reservoirs, and their main functions are irrigation, water supply and power generation. Among these water storage projects, there are 30 large reservoirs with a total capacity of $176.9 \times 10^{8} \mathrm{~m}^{3}$ and a utilizable capacity of $81.0 \times 10^{8} \mathrm{~m}^{3}$. In addition, there are 3 large reservoirs under construction on the Ganjiang and Raohe Rivers. Figure 12 shows the number of large reservoirs built during different periods; construction exhibited an "up-down-up" pattern and reached its maximum value in the 2000s, which may be one of the reasons for the decrease in runoff in the PYLB during this period.

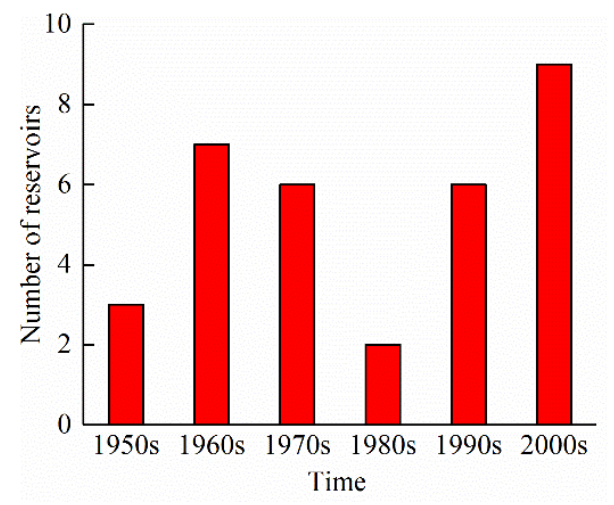

Figure 12. Statistics on the number of large reservoirs in the PYLB.

The development of urbanization increases not only the amount of water withdrawal but also the impervious area of built-up land. The former leads to decreases in runoff, while the latter leads to increases in runoff. The effect of water withdrawal on runoff reduction is most evident in the Fuhe River subbasin because the largest irrigation district in Jiangxi Province takes approximately 
$37.6 \times 10^{8} \mathrm{~m}^{3}$ of water from the Fuhe River per year, accounting for $29.6 \%$ of the annual total runoff of this river. Additionally, to meet the demands of agriculture, industry and life, the annual average water consumption from the five subbasins increased from $108.95 \times 10^{8} \mathrm{~m}^{3}$ in 1980 to $146.91 \times 10^{8}$ in 2015 (Figure 13), which inevitably led to reductions in runoff. With the development of the regional social economy, the level of urbanization has continuously improved, which means that the urban impervious area has increased. As shown in Figure 13, the area of built-up land in the five subbasins increased rapidly after 2000 and reached $2916 \mathrm{~km}^{2}$ by 2015, which represents an increase of $1120 \mathrm{~km}^{2}$ compared with that in 1980 .

Due to an unreasonable economic development policy coupled with population increase and severe deforestation, the forest coverage in the PYLB decreased from $40.4 \%$ in 1949 to $31.5 \%$ in the early 1980s [28]. The decline in forest coverage during this period led to the deterioration of the ecological environment, serious soil erosion and increased runoff in the PYLB. Since the early 1980s, Jiangxi Province has implemented a series of afforestation projects, including returning farmland to forest; as a result, the annual average afforestation area was $2630 \mathrm{~km}^{2}$ in the 1990s, and the forest coverage increased to $60 \%$ at the end of this period, ranking second in the country [56]. The increase in forest coverage can play a positive role in water conservation, reducing runoff to a certain extent. In addition, Jiangxi Province has successively carried out several other water and soil conservation projects since the early 1980s, such as the National Project of Water and Soil Loss Key Management and the National Water and Soil Conservation Program of Agricultural Comprehensive Development, forming a comprehensive protection system. This protection system has interfered with the runoff generation process in the basin in different ways; thus, the water demand in the basin has increased and the runoff has decreased.

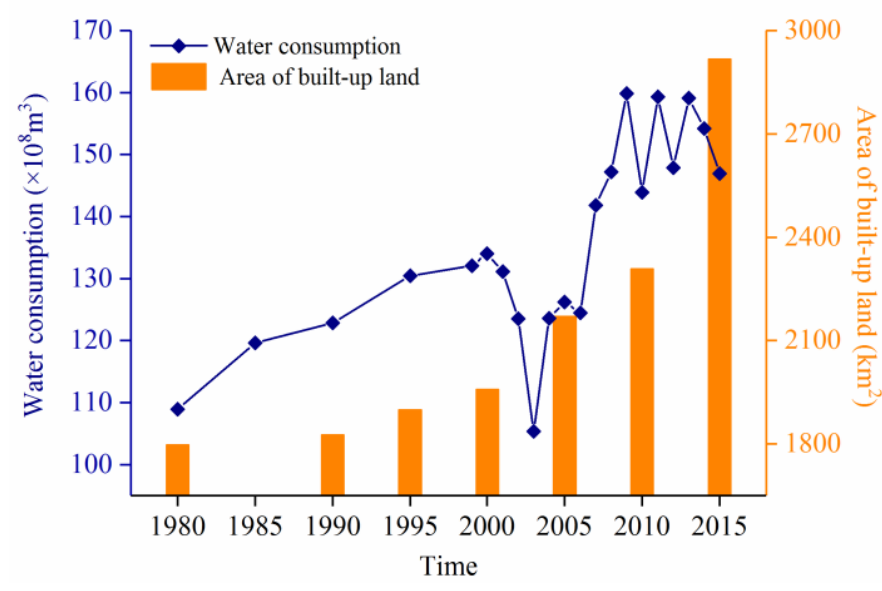

Figure 13. Changes in annual water consumption and the area of built-up land in the five subbasins of the PYLB during 1980-2015.

Overall, the impacts of human activities on runoff changes are complex; some changes increase runoff, while other changes have the opposite effect. Runoff changes under the joint action of multiple human activities, and the impacts of these human activities can overlap or weaken each other. Therefore, it is difficult to separate these impacts. Due to the diversity and uncertainty of human activities and the limitations of the data, this study explored the impacts of different types of human activities on runoff changes in the PYLB and distinguished their comprehensive contribution rate in each subbasin. Furthermore, runoff exhibited an obvious downward trend in each subbasin after 2000, and human activities became the leading factor causing the changes in runoff in the most recent decade. Thus, we believe that human activities that reduced runoff (such as the construction and operation of large reservoirs and dams, and water withdrawals) were the dominant factors responsible for the runoff changes in the PYLB during the 2000s. 


\section{Conclusions}

In this study, the Poyang Lake Basin was taken as the study area to explore the characteristics of the variations in runoff and its responses to climate changes and human activities over the period from 1961 to 2015. Using the Mann-Kendall trend test, cumulative anomaly, Hurst exponent analysis, and SCRCQ method, the results of this study conclusively reveal the following:

(1) From 1961-2015, the runoff series in the Ganjiang, Xinjiang, Raohe and Xiushui subbasins showed non-significant increasing trends, whereas runoff in the Fuhe subbasin showed a non-significant decreasing trend. Runoff in each subbasin increased most dramatically in the 1990s and declined significantly in the 2000s.

(2) The inflection points in runoff variations for the five subbasins were identified. For Ganjiang, Fuhe and Xinjiang, the inflection points occurred in 1991 and 2002; for Raohe, they occurred in 1988 and 1999; and for Xiushui, they occurred in 1988 and 2002. The entire study period was divided into one baseline period and two measurement periods for each subbasin according to these inflection points.

(3) In the future, the runoff in the five subbasins will present anti-persistent features with different persistence strengths and persistence times ( 6 or 9 years). Given their persistence times, runoff in the Fuhe subbasin is expected to continuously increase, and runoff in the other four subbasins will continuously decrease, which is undoubtedly a hazard for the Poyang Lake Basin, which has already suffered from the problem of water resource shortages.

(4) The annual average inflow to Poyang Lake presented an overall increasing trend over the past 55 years, indicating that climate change and human activities played positive roles in this process. Compared with the values during the baseline period, the contribution rates of precipitation and human activities to runoff changes were different in time and space. In the first measurement period, precipitation was the main factor driving the runoff increases in the Ganjiang, Fuhe, Xinjiang and Raohe subbasins, and the contribution rates were 50.91-63.47\%. However, in the second measurement period, human activities had become the leading factor causing changes in runoff, and the contribution rates were $59.57-92.49 \%$.

In summary, against the background of global climate change and increasingly frequent human activities, exploring the relative impacts of climate change and human activities on basin hydrology can provide a scientific basis and an important reference for guiding control of regional flood and drought disasters and for the planning and management of water resources, which is also of great significance for solving regional water shortage problems.

Author Contributions: Conceptualization, W.P., X.L., C.J. and R.W.; Formal analysis, R.W. and X.C.; Funding acquisition, W.P., X.L. and W.W.; Writing-original draft preparation, R.W.; Writing-review and editing, W.P., X.L. and C.J. All authors have read and agreed to the published version of the manuscript.

Funding: This work is supported by the National Key Research and Development Project (2016YFC0401701), Program for Innovative Research Team of IWHR (WE0145B592017), Special Project for Basic Research of IWHR (WE0145B532017 and WE0145C032017), Joint Open Research Fund Program of State key Laboratory of Hydroscience and Engineering and Tsinghua-Ningxia Yinchuan Joint Institute of Internet of Waters on Digital Water Governance (No. sklhse-2019-Iow07), and The Basic Research Project of IWHR (No. WE0145B562016).

Acknowledgments: We would like to warmly thank reviewers for their remarkable comments.

Conflicts of Interest: The authors declare no conflict of interest.

Data Availability: The meteorological data used to support the findings of this study are available from the China Meteorological Data Sharing Service System (http://data.cma.cn/) for researchers who meet the criteria for access to confidential data. The runoff observation data used to support the findings of this study have not been made available because of the data management policy.

\section{References}

1. Humborg, C.; Ittekkot, V.; Cociasu, A.; Bodungen, B.V. Effect of Danube River dam on Black Sea biogeochemistry and ecosystem structure. Nature 1997, 386, 385-388. [CrossRef] 
2. Gong, G.C.; Chang, J.; Chiang, K.P.; Hsiung, T.M.; Hung, C.C.; Duan, S.W.; Codispoti, L.A. Reduction of primary production and changing of nutrient ratio in the East China Sea: Effect of the Three Gorges Dam? Geophys. Res. Lett. 2006, 33, 3716-3730. [CrossRef]

3. Li, E.H.; Mu, X.M.; Zhao, G.J. Temporal changes in annual runoff and influential factors in the upper and middle reaches of Yellow River from 1919-2010. Adv. Water Sci. 2014, 25, 155-163.

4. Quilbé, R.; Rousseau, A.N.; Moquet, J.S.; Savary, S.; Ricard, S.; Garbouj, M.S. Hydrological responses of a watershed to historical land use evolution and future land use scenarios under climate change conditions. Hydrol. Earth Syst. Sci. Discuss. 2008, 12, 101-110. [CrossRef]

5. Milano, M.; Reynard, E.; Köplin, N.; Weingartner, R. Climatic and anthropogenic changes in Western Switzerland: Impacts on water stress. Sci. Total Environ. 2015, 536, 12-24. [CrossRef] [PubMed]

6. Zhao, G.; Tian, P.; Mu, X.; Jiao, J.; Wang, F.; Gao, P. Quantifying the impact of climate variability and human activities on streamflow in the middle reaches of the Yellow River basin, China. J. Hydrol. 2014, 519, 387-398. [CrossRef]

7. Zhou, Y.; Shi, C.; Fan, X.; Shao, W. The influence of climate change and anthropogenic activities on annual runoff of Huangfuchuan basin in northwest China. Theor. Appl. Climatol. 2015, 120, 137-146. [CrossRef]

8. Milly, P.C.D.; Dunne, K.A.; Vecchia, A.V. Global pattern of trends in streamflow and water availability in a changing climate. Nature 2005, 438, 347. [CrossRef]

9. Jiang, C.; Xiong, L.; Wang, D.; Liu, P.; Guo, S.; Xu, C.Y. Separating the impacts of climate change and human activities on runoff using the budyko-type equations with time-varying parameters. J. Hydrol. 2015, 522, 326-338. [CrossRef]

10. Zhang, G.X. Wetland Ecological Hydrology and Water Resource Management; Science Press: Beijing, China, 2014.

11. Walling, D.E.; Fang, D. Recent trends in the suspended sediment loads of the world's rivers. Glob. Planet. Change 2003, 39, 111-126. [CrossRef]

12. Sivakumar, B.; Jayawardena, A.W.; Fernando, T.M.K.G. River flow forecasting: Use of phase-space reconstruction and artificial neural networks approaches. J. Hydrol. 2002, 265, 225-245. [CrossRef]

13. Acreman, M.C.; Dunbar, M.J. Defining environmental river flow requirements-A review. Hydrol. Earth Syst. Sci. 2004, 8, 861-876. [CrossRef]

14. Sun, Z.; Huang, Q.; Opp, C.; Hennig, T.; Marold, U. Impacts and implications of major changes caused by the Three Gorges Dam in the middle reaches of the Yangtze River, China. Water Res. Manag. 2012, 26, 3367-3378. [CrossRef]

15. Zhao, C.Y.; Wang, Y.X.; Wen, Z.Z.; Hu, G.L.; Chen, H.X. Analysis of runoff variation and influencing factors in Pingliang reach of Jinghe river. J. Water Resource. Water Eng. 2017, 28, 36-41.

16. Zhai, R.; Tao, F. Contributions of climate change and human activities to runoff change in seven typical catchments across China. Sci. Total Environ. 2017, 605-606, 219. [CrossRef] [PubMed]

17. Wu, J.; Miao, C.; Zhang, X.; Yang, T.; Duan, Q. Detecting the quantitative hydrological response to changes in climate and human activities. Sci. Total Environ. 2017, 586, 328-337. [CrossRef]

18. Al-Safi, H.I.J.; Kazemi, H.; Sarukkalige, P.R. Comparative study of conceptual versus distributed hydrologic modelling to evaluate the impact of climate change on future runoff in unregulated catchments. J. Water Clim. Change 2019. [CrossRef]

19. Wang, X. Advances in separating effects of climate variability and human activity on stream discharge: An overview. Adv. Water Resource. 2014, 71, 209-218. [CrossRef]

20. Guo, H.; Hu, Q.; Zhang, Q.; Wang, Y.J. Annual variations in climatic and hydrological processes and related flood and drought occurrences in the Poyang Lake basin, china. Acta Geogr. Sin. 2012, 67, 699-709.

21. Liu, J.; Zhang, Q.; Xu, C.Y.; Zhang, Z.X. Characteristics of runoff variation of Poyang lake watershed in the past 50 years. Trop. Geogr. 2009, 29, 213-218.

22. Zhang, X.L.; Li, Y.L.; Yu, G.; Zhang, Q. Runoff simulation and response to climate changes for Poyang Basin during the past 1000 years. J. Lake Sci. 2016, 28, 887-898.

23. Shankman, D.; Keim, B.D.; Song, J. Flood frequency in China's Poyang Lake region: Trends and teleconnections. Int. J. Climatol. 2010, 26, 1255-1266. [CrossRef]

24. Min, Q. Analysis on the flood characters in 1990s, Poyang Lake. J. Lake Sci. 2002, 14, 323-330.

25. Sun, P.; Zhang, Q.; Tu, X.J.; Jiang, T. Changing properties of meteor-hydrological droughts of the Lake Poyang Basin using the Markov model. J. Lake Sci. 2015, 27, 1177-1186. 
26. Guo, H.; Hu, Q.; Jiang, T. Annual and seasonal streamflow responses to climateand land-cover changes in the Poyang Lake basin, China. J. Hydrol. 2008, 335, 106-122. [CrossRef]

27. Hu, J.F.; Zhao, G.N.; Cai, Z.; Ma, F.M. Variation characteristics and attribution of runoff in Xinjiang Drainage basin during 1953-2011. Meteorol. Disast. Reduct. Res. 2014, 37, 61-66.

28. Liu, G.H.; Qi, S.H.; Zhu, J.X.; Xiong, M.Y.; Wang, D. Quantitative estimation of runoff changes in Ganjiang River, Lake Poyang Basin under climate change and anthropogenic impacts. J. Lake Sci. 2016, 28, 682-690.

29. Ye, X.C.; Zhang, Q.; Liu, J.; Li, X.H.; Xu, C.Y. Distinguishing the relative impacts of climate change and human activities on variation of streamflow in the Poyang Lake catchment, China. J. Hydrol. 2013, 494, 83-95. [CrossRef]

30. Zhang, Q.; Liu, J.Y.; Singh, V.P.; Gu, X.H.; Chen, X.H. Evaluation of impacts of climate change and human activities on streamflow in the Poyang Lake basin, China. Hydrol. Process. 2016, 30, 2562-2576. [CrossRef]

31. Zhao, G.J.; Hörmann, G.; Fohrer, N.; Zhang, Z.X.; Zhai, J.Q. Streamflow trends and climate variability Impacts in Poyang Lake Basin, China. Water. Resour. Manag. 2010, 24, 689-706. [CrossRef]

32. Wang, R.N.; Peng, W.Q.; Liu, X.B.; Wu, W.Q.; Chen, X.K.; Zhang, S.J. Responses of Water Level in China's Largest Freshwater Lake to the Meteorological Drought Index (SPEI) in the Past Five Decades. Water 2018, 10, 137. [CrossRef]

33. Mann H, B. Nonparametric Tests Against Trend. Econometrica 1945, 13, 245-259. [CrossRef]

34. Ran, L.S.; Wang, S.J.; Fan, X.L. Channel change at Toudaoguai Station and its responses to the operation of upstream reservoirs in the upper Yellow River. J. Geogr. Sci. 2010, 20, 231-247. [CrossRef]

35. Hurst, H.E. Long term storage capacities of reservoirs. Trans. Am. Soc. Civ. Eng. 1951, 116, 776-808.

36. Mandelbrot, B.B.; Wallis, J.R. Robustness of the rescaled range $\mathrm{r} / \mathrm{s}$ in the measurement of noncyclic long run statistical dependence. Water Resource. Res. 1969, 5, 967-988. [CrossRef]

37. Fu, Y.Z.; Xu, S.G.; Liu, J.W. Temporal-spatial variations and developing trends of Chlorophyll-a in the Bohai Sea, China. Estuar. Coast. Shelf Sci. 2016, 173, 49-56. [CrossRef]

38. Wu, L.H.; Wang, S.J.; Bai, X.Y.; Luo, W.J.; Tian, Y.C.; Zeng, C.; Luo, G.J.; He, S.Y. Quantitative assessment of the impacts of climate change and human activities on runoff change in a typical karst watershed, SW China. Sci. Total Environ. 2017, 601, 1449-1465. [CrossRef]

39. Wang, S.J.; Yan, Y.X.; Ming, Y.; Zhao, X.K. Quantitative estimation of the impact of precipitation and human activities on runoff change of the Huangfuchuan River basin. J. Geogr. Sci. 2012, 22, 906-918. [CrossRef]

40. Wang, S.; Wang, Y.; Ran, L.; Su, T. Climatic and anthropogenic impacts on runoff changes in the songhua river basin over the last 56 years (1955-2010), Northeastern China. Catena 2015, 127, 258-269. [CrossRef]

41. Wang, S.; Yan, M.; Yan, Y.; Shi, C.; Li, H. Contributions of climate change and human activities to the changes in runoff increment in different sections of the Yellow River. Quaternary Int. 2012, 282, 66-77. [CrossRef]

42. Wang, J.J.; Li, C.Y.; Sun, B.; Fan, C.R.; Liang, L.; Han, Z.M. Impacts of precipitation on runoff yield of Hulun Lake basin during 1963-2014. Bulletin Soil Water Conserv. 2017, 37, 115-119.

43. Wang, Y.; Xu, H.M.; Cheng, B.Y.; Huang, D.P.; Tan, Y.T.; Luo, Y. Impacts of precipitation change on the runoff change in the Fujiang River basin during the period of 1951-2012. Progressus Inquisitiones De Mutatione Climatis 2014, 10, 127-134.

44. Luo, W.; Zhang, X.; Deng, Z.M.; Xiao, Y. Variation of the total runoff into Poyang Lake and drought-flood abrupt alternation during the past 50 years. J. Basic Sci. Eng. 2013, 21, 845-856.

45. Liu, J.Y.; Zhang, Q.; Gu, X.H. Evaluation of ecological flow with considerations of hydrological alterations in the Poyang Lake basin. Acta Ecolog. Sin. 2015, 35, 5477-5485.

46. Xiao, L.Y.; Zhou, X.; Peng, Y.W. Comparative analysis of change-point detection of runoff series with different methods in Poyang Lake Watershed. J. Nanchang Inst. Technol. 2016, 35, 85-89.

47. Zhang, J.W.; Guo, J.L.; Liu, J.; Li, Y.H.; Guo, J. Prediction for temporal and spatial variability of Poyang Lake inflow. South-to-North Water Tran. Water Sci. Technol. 2016, 14, 41-48.

48. Guo, H.; Su, B.D.; Wang, Y.J.; Jiang, T. Runoff coefficients change and the analysis of the relationship between climate factors and runoff coefficients in Poyang Lake Basin (China):1955-2002. J. Lake Sci. 2007, 19, 163-169.

49. Yuan, Y.J.; Zhang, C.; Zeng, G.M.; Liang, J.; Guo, S.L.; Huang, L.; Wu, H.P.; Hua, S.S. Quantitative assessment of the contribution of climate variability and human activity to streamflow alteration in Dongting Lake, China. Hydrolog. Process. 2016, 30, 1929-1939. [CrossRef]

50. Kong, D.; Miao, C.; Wu, J.; Duan, Q. Impact assessment of climate change and human activities on net runoff in the Yellow River Basin from 1951 to 2012. Ecol. Eng. 2016, 91, 566-573. [CrossRef] 
51. Tian, L.; Wang, S. Analysis of the runoff change and main influencing factors in the Liaohe River Basin. Res. Soil Water Conservat. 2018, 25, 153-159.

52. Xia, J.; Ma, X.Y.; Zou, L.; Wang, Y.L.; Jing, Z.X. Quantitative analysis of the effects of climate change and human activities on runoff in the upper Hanjiang River Basin. South-to-North Water Tran. Water Sci. Technol. 2017, 15, 1-6.

53. Li, C.; Yang, Z.F. Influence of operation of main reservoirs on the yellow river on runoff. Yellow River 2004, 26, 15-16.

54. Xu, J.X.; Sun, J. Influence of precipitation and human activities on water fluxes from the Yellow River into the sea in the past 50 years. Adv. Water Sci. 2003, 14, 690-695.

55. Yao, Y.B.; Zhang, X.Y.; Wang, R.Y.; Cai, G.Z. Impact of climate changing to water resource in Taohe river valley. J. Soil Water Conservat. 2008, 22, 168-173.

56. Mo, M.H.; Yang, X.X.; Xiao, S.S.; Tu, A.G. Analysis on runoff and sediment change characteristics and influence factors of Poyang Lake five rivers basin. Res. Soil Water Conservat. 2017, 24, 197-203.

(C) 2020 by the authors. Licensee MDPI, Basel, Switzerland. This article is an open access article distributed under the terms and conditions of the Creative Commons Attribution (CC BY) license (http://creativecommons.org/licenses/by/4.0/). 